\title{
Women and Domestic Violence: Reflections on Biological and Socio-Cultural Arguments
}

\author{
${ }^{1}$ Grace Reuben Etuk $*{ }^{2}$ MagdaleneAgborIgbolo, ${ }^{3}$ Austin EzeBassey \\ ${ }^{I}$ Department of Sociology, University of Calabar, P.M.B.1115, Calabar, Nigeria. \\ ${ }^{2}$ Department of Sociology, University of Abuja, Abuja, Nigeria. \\ ${ }^{3}$ Department of Sociology, University of Calabar, P.M.B.1115, Calabar, Nigeria.
}

\begin{abstract}
Of the different violatory practices women are confronted with, domestic violence happens to be one of the few that occurs across societies. It transcends social and cultural boundaries and can be found in practically every human society, possibly because of the universality of the family institution, where the mayhem is perpetrated.

This form of violence has been a major reason why many women have been, and continue to be brutalized, maimed, traumatized and even killed. Unfortunately, the problem, though widespread, has remained largely hidden, again due to its familial nature.

A major concern relating to domestic violence, that has occupied the attention of scholars has been that of unearthing the cause of the persistence of this monstrous phenomenon. In response, Sociologists, Feminists and other scholars have attempted several explanations. One of such is the argument that domestic violence is biologically motivated. But is biology enough explanation for the countless attacks women suffer in the hands of their partners?

While not out rightlyjettisoning the biological standpoint, this paper examines the cultural landscape of society, and highlights how more than biology, social and cultural factors function tofacilitate the persistence ofdomestic violence.More importantly, attempt is made in the paper to identify the converging point of these positions in the explanation of how and why domestic violence is perpetuated in society.
\end{abstract}

Keywords: Domestic Violence, Biology, Society, Culture, Women.

\section{Introduction}

From the sociological point of view, human behavior is learned. Sociologists believe that human beings are born with no innate ideas. But as they grow from infancy, they gradually acquire the norms and values of the society within which they operate, a process known in Sociology as socialization. These norms and values according to Sociologists, in turn function to shape the actions individuals in their day to day interactions.

If this sociological stance that behavior is shaped by societal norms and values is upheld, the implication will be that as a form of social behavior, domestic violence can also be driven by the norms and values of society. But then among, Sociobiologists, behavior is also considered to be biologically determined. This goes to imply that as a form of aggressive behavior displayed by one family member towards another, domestic violence can also be biologically motivated. Be that as it may, whether domestic violence is a natural tendency, or a product of environmental (i.e. socio-cultural) influence, remains a subject of debate among scholars.

\section{The Problem}

Domestic violence became a popular subject of debate among Scholars, and Feminist in particular, during the 1970 's, following studies that drew attention to the severity and prevalence of the issue especially as it affects women (Giddens, 2006).

As a form of violence occurring at the family scene, domestic violence affects not just women, but children and men as well; even though it is often misapprehended as a problem affecting women alone. In fact, by way of definition, domestic violence as captured by Giddens (2006) is physical abusedirected by one member of the family against another or others. It covers all physically, sexually and or emotionally abusive behavior by an individual to assert and maintain control over another in the family scene. It therefore means that domestic violence can affect any family member; children, wives or husbands. Many incidents of domestic violence involving attack on children have been reported time and again. To say the least, children, being the more powerless and helpless family members, are often the prime targets and vulnerable group as far as violence at the domestic scene is concerned. In the case of men, studies show that they too can be victims of domestic violence. However, according to Giddens (2006), there are far fewer reported cases of women physically attacking their husbands, although Scholars like Straus and Gills (1986) have argued that husbands are less 
likely than wives to report instances of violence against them by their wives. Be that as it may, Feminists stress that even the reported cases of violence by wives towards their husbands are less severe and dramatic, in terms of harm that can result and otherwise. This corroborates Cherlin's, (2002) report that although both men and women engage in violence, men typically do more damage than their female partners and many more women than men report victimization.

They also argue that violence by wives against their husbands usually occur as defensive, rather than offensive mechanism, pointing out that women who attack their husbands do so only after suffering repeated attacks from such husbands.

Granted that both children and men can be victims of domestic violence, it is however not in contest that women are the main victims of this monstrous phenomenon. Giddens, (2006), described it as the most common form of violence against women. It affects women of all races and religion. Not even women from developed societies and higher social classes are immune from it, although Cherlin's (1999) investigation of existing records reveal that it is more common among low income couples, due to among other things; high level of stress induced by poverty and unemployment. This agrees with the findings of Okolo (2006), whose study on marital violence among 500 employed women in Cross River State, Nigeria, revealed that among this class of women, (who by virtue of their employment status are of the relatively higher income group) beating and other physical abuses ranked very low in the type of abuse they indicated being subjected to. Only $14.6 \%$ of them indicated they faced this form of abuse, while a greater proportion indicated being faced with other social and emotional forms of spousal abuse.

Domestic violence as it affects women or wife battery as it often described is commonplace. It occurs in every society around the globe. In Nigeria, domestic violence is prevalent among the over 250 ethnic groups, a contributing factor being the yet polygamous nature of many Nigerian families.However, not only is the rate at which it occurs underestimated and underreported (Olakunle, 2011), also literature and statistics on the subject is scanty. In U.S.A. where data are readily available, reports show that husbands and boyfriends assault as many as four million women every year (Brown, Dubau and Mckeon, 1997). Still in United States, surveys on domestic violence reveal that women make about 1, 453,437 visits every year to treat injuries resulting from assaults by spouse (Barnette and Laviolette, 1993). In a more detailed report, the United States Crime Survey Data estimated that the number of visits by women for medical care resulting from violence by spouse stand at 28,700 visits to a hospital emergency room; 39,000 visits to physicians' offices, 21,000 in-patient hospitalization and 99,800 days of hospitalization (Roberts, 1996). In 2000W.H.O. reported that assault on women by their spouses in stood at 22 percent in the United States, 13 percent in Switzerland, 47 percent in Bangladesh and 58percent in turkey. Most certainly, these figures will keep rising.

In general, every two weeks, 2 women die of domestic violence, and at any one time, 10 percent of women are experiencing domestic violence, (Giddens 2006). The burning question is; why has this phenomenon come to stay with human race? Why are women as vulnerable as they have been over the years to domestic violence across societies, races, classes and religions? Why is domestic violence a problem that between a third and a quarter of women will face at some point in their lives? What factors underlie and perpetuate this phenomenon?

\section{Tracing the Roots of Domestic Violence: The Question ofbiology}

Many Sociologists and Scientists assert that behaviour and social roles of men and women can be attributed to their biological composition. This is the field known as Sociobiology, where the fundamental assumption is that behaviour is at least partially influenced by biological processes and generic factors (Franzoi, 1996). Specifically, in Haralambos and Holborn (2009), it is noted that the activities of a wide range of hormones is closely integrated with the activities of the nervous system, making hormones to have the capability to influence behaviour, personality and emotional disposition. This is essentially where Sociobiologists hinge most of their arguments on.

Emerging from this biological angle,Shullasmith Firestone (1972) in her work "The Dialectics of Sex"linked the oppression women face in society to their biological composition. She argued that men and women are biologically different and so unequally privileged, adding that sex class unlike economic class is rooted in the biological differences found in men and women. According to Firestone, the biological or natural order of women having to depend on men for conception and eventually childbirth creates room for unequal power relations and the manifestation of power psychology. This noted Firestone, goes on to provide a plat form for men to have dominance over women, with such dominance finding expression in the different acts of oppression and suppression by men towards women in different spheres of life including marriage.

Contributing to the biological arguments, Tiger and Fox (1972) suggested that women's oppression is rooted in the fact that womenare naturally (i.e. biologically) programmed to be quiet and passive, while men are wired biologically to be aggressive and dominant. By this they meant that men and women are biologically predisposed to be different, to the extent that women are quiet while men are aggressive. Goingby the views of 
Tiger and Fox (1972), what this means is that since men are by their nature aggressive, the likelihood therefore is that sometimes this aggressiveness can be expressed by way of violent behaviours towards their wives who on the other hand will accommodate such because they are according to Tiger and Fox predisposed biologically to be quiet and passive.

Biological explanations of social behaviour in general have faced wide criticisms. A number of critics like Bleier (1984) observed that some of the experiments to establish the relationship between hormones and behaviour were performed with animals, stressing that using results derived from animals to draw conclusions on human behaviour can be dangerous and misleading.

If one decides to stay with the arguments that biology is a factor to personality and behavior, as Sociobiologistsargue; on the issue at hand-domestic violence-the question remains, how does biology or hormonal composition in men become a factor in wife abuse? If men's testosterone levels make it that they have increased levels of aggressiveness, as Sociobiologists argue, such aggressiveness can well be channeled to such areas of social life like sports, work and similar productive endeavours. Biologically speaking also, a number of women are known to have higher levels of male hormones than normal. This raises a crucial concern. How come they are not registering this aggressiveness whichis reported by Scientists as accompanying male hormones, by way of unleashing violence on men (their husbands) to the extent that it also becomes a phenomenon of social concern?

Analyzing the studies of Halper et al. (1994) Archer and Lloyd as discussed in Haralambos and Holborn (2007) saw no correlation between hormones and aggressiveness. They argued based on their field experience that males tend to be aggressive when they perceive others to be challenging their reputation and honour, and concluded that hormones only influence behaviour in the context of particular historical and cultural settings. This implies that no matter how aggressive men are, if there is no enabling social and cultural environment, this aggressiveness will not translate in physical behaviour, let alonebehaviours that constitute violence at the domestic scene. That is to say, even if men are by their hormonal composition predisposed to be aggressive, only the presence of social and cultural forces can pave way for such aggressiveness to be displayed in such ways as domestic violence. It therefore not surprising that women with high levels of male hormones have not also registered their aggressiveness -whichSociobiologists claim male hormones are supposed to cause by unleashing violence on their husbands; the simple reason being that the social and cultural forces in operation have given basically no room for such. This brings us to the question of society and culture and the extent they function to create room for domestic violence against women.

\section{Societal andCultural Dimensions}

As previously observed, it is widely believedamong Sociologist that behaviour is learned through the processof socialization. The idea of John Locke that man is born 'Tabular Rasa' emphasizes this. John Locke posits that at birth, a human being is like a clean slate, knowing nothing and helpless. The only way the infant comes to survive or fit into the society he is born into is by learning the culture of that society. Culture itself, which is the way of life of people in a given society, determines to a large extent the ways individuals behave, think, feel and direct their action in any given society (Haralambos and Heald, 1980).

This is because norms i.e. rules that govern behavior, and values i.e. that which is considered appropriate or acceptable, as well as beliefs i.e. that which is acceptedas true; are all culturally determined and transmitted via socialization into individuals. And as already noted, these function together to determine the type of behaviour individuals will display in society at any given time. That is to say, behaviour at the level of an individual and social life, thatis, the behaviour and interaction of all society members put together, are firmly rooted in the cultural forces in operation in every society. This forms the basis of the positionof this paper. In other words, as an aspect of social life, as well as a form of social behavior,domestic violence like all other forms of social behavior and aspects of social life is a product of prevailing social and cultural systems. Simply put, domestic violence is a social behavior that is socially and culturally motivated

In many traditional cultures, take for instance, a typical Nigerian setting; women are culturally socialized from the cradle to operate mainly 'behind the scene'. In some instances,especially in rural settings, they may not 'talk when men are talking' and until recently they were not expected to take on active roles beyond the domestic scene. Also, not long ago in Nigeria, a saying like 'a woman's education ends in the kitchen' was quite popular, and exemplifies how women and girls were typically viewed and even trained. This is demonstrated in girls being given dolls as toys while boys receive items like cars, footballs, guns and aero planes as toys. In addition, at the domestic scene, girls are the ones expected to help out with house chores, while the boys are out or busy with other non-domestic activities. These prepare them for their future roles and the long term implications have been thatgirls grow up as women, being limited and more domesticated in their roles and behaviours. On the other hand, boys who by virtue of socialization as seen even the toys theyget, are given room to explore and be aggressive, carry such tendencies into adulthoodand even into marital life. In the long run abusing their wives might just become one avenue to express the explorative and domineering 
tendencies they were socialized into adopting. Why would a boy who playedwith a gun as toy not be aggressive, even towards his wife when he becomes a man?

Many traditional societies believe that men are superior to women, who on the other hand are considered in these cultures as men's possessions to be treated as they consider appropriate (Davis, 1997). Okolo (2004) affirms this in stating that norms governing family relations in many traditional societies permit men as heads of authority in the home to employ any practicable method to both enforce their will and exercise this authority. It is not surprising therefore that in Nigeria, some men often remind their wives that they married them with their hard earned money and could do whatever they wish to them. Buttressing this, Caruso (1996) observed that in some cultures, women and children are considered the property of their husbands and fathers, adding that social customs and written laws gave men the right and responsibility to control their wives and to use force when necessary to maintain order in families. In the words of Dwyer, Smokowski, Bricout and Wordarski (1994) 'many countries believe that a man does have the right to control his wife, to be head of the family'.

In Browne (1987),it is stressed that ancient laws of marriage required women to conform themselves entirely to the temper of their husbands who inturn are to rule their wives. Browne went on to note that a number of ancient laws give room for men to exercise control over their wives using violence if need be. Frisch and Caruso (1996) confirmed this in pointing out that husband's right to discipline their wives was codified inlaw as early as ancient Rome, adding that until late $19^{\text {th }}$ century, common law and written statutes regulated but did not prohibit the physical abuse of wives. Frisch and Caruso concluded that these laws to a recognizable extent permitted men to discipline their wives as they saw fit, with strong community backing and little or no interference from outsiders.

In Nigeria, section 55 of the penal code condones wife beating in customary law marriage by stating that "nothing is an offence which does not amount to the infliction grievous hurt upon any person and which is done by a husband for the purpose of correcting his wife, such husband or wife being subject to any native law or custom in which such correction is recognized as lawful". More precisely, in Igbo customary law, a husband has the right to chastise his wife for failing to perform her duties, laziness, wastefulness and destructiveness; while in Sharia law, a husband has the right to admonish his wife although he may not use an instrument longer than his finger to make a mark on her body.

The structure of many societies, precisely, their social and cultural norms are patterned in ways that both allow men superiority over their wives and give them room to enforce this superiority, which some men, in bid to enforce, end up inflicting violence on their wives.

The instances outlined so far are explicit indications thatprevailing social formations, as well as complex set of traditions, values, customs and habits of every individual society, to a large extent constitute the principal forces behind the continuous abuse of women at the domestic scene by their spouses. Thus, even if biology may be accounted as a factor powering the unending existence of domestic violence, society and its culture remain the driving force, considering that they provide a platform for whatever biological attributes that may be to be expressed.In line with this, Oakley (1981) argued strongly that hormone levels can even be a function of social contexts. That is to say, hormonal functioning and possibly, the actions that may result can be triggered by social circumstances. For instance Archer and Lloyd (2002) as discussed by Haralambos and Holborn (2004) found out in their research that the males in their experiment displayed aggression, which to a large extent is driven by hormone levels, when they perceive others to be challenging their honour and reputation which are strong masculine values. This is a clear case of biology coming into play in the event of obvious socio-cultural drive,leaving one with no doubt that biology does interact with social processes. Thus, for a social behavior like domestic violence, men's biological or hormonal composition cannot be adjudged to be the direct causal factor. Hormonal levels in men can only rise to warrant domestic violence against women in the face of social and cultural norms and values providing the plat forms.

\section{A Call for Value Re-Orientation}

Any attempt to achieve meaningful changes with regards to violence against women by their spouses cannot afford compromising adjustments in the normative and value systems of society. The starting point has to be revisiting the issue of differential socialization of boys and girls. The norms and values inculcated into them must be adjusted to reflect equality between the sexes, rather than the superiority or inferiority of any of them. That is to say, boys and girls should be given a chance to grow up on an even playing ground. This will minimize the tendency of men to regard women as subordinates, to be treated disdainfully in whatever form and whenever necessary.

The campaign to tackle domestic violence, if taken to the custodians of traditional institutions, will make a significant difference in grappling with the issue. Custodians of traditional institutions in many African societies like Nigeria, rather than emphasize on men treating their wives with some dignity, preach the gospel of men being in chargewhatever the circumstance, and the women submitting unconditionally. As Eze- 
Anaba(2004) in Olakunle (2011) reports, women are expected to endure whatever condition comes their way in their matrimonial homes. This however increases their susceptibility to domestic violence. It is not surprising therefore that the phenomenon though wide spread is largely hidden because women continue to put up with the menace all in the name of 'enduring' as expected of them by tradition.Custodians of traditional institutions must therefore be carried along in this quest for change, by being re-orientated, so that those values they uphold and promote can be altered, thereby leaving little or no room for traditional or cultural supports for domestic violence, particularly as it affects women.

Lastly, in the case of Nigeria, it is absolutely needful for the aspects of the country's penal code, as well as the customary and sharia laws that directly or indirectly encourage domestic violence in whatever form to be revisited and appropriately adjusted. This is in order to do away with all traces of institutionalized backing for any form of domestic violence, leaving full room for those who may act otherwise to be duly penalized.

\section{References}

[1]. Barnett, O. W. and Laviolette, A. D. (1993).It Could Happen to Anyone: Why Battered Women Stay. London: Sage Publication.

[2]. Bleier, R. (1984). Science and Gender.New York: Pergamon Press.

[3]. Brown, L., Dubau, F, and Mckeon, M. Y.D. (1997) Stop Domestic Violence: An Action Plan For Saving Lives. New York: St Martin's Griffin.

[4]. Browne, A. (1987) When Battered Women Kill. New York: Free Press.

[5]. Cherlin, A. (1999) Public and Private Families: An Introduction. New York: McGraw Hill

[6]. Cherlin, A. J. (2002) Public and Private Families: An Introduction. New York: McGraw Hill.

[7]. Davis, M. (1994).Women and Violence: Realities And Responses Worldwide.New York: Zed Books.

[8]. Dwyer, D. C., Smokowsk, P. R., Bricout, Y. C, and Wodarski, Y. S. (1996)."Domestic Violence and Women Battering: Theories and Practice Implications". In A. R. Roberts, (Ed).Helping Battered Women: New Perspectives and Remedies. (pp 67-82) New York: Oxford University Press.

[9]. Franzoi, S. L. (1996) Social Psychology. Brown and Benchmark, Madison.

[10]. Firestone, S (1872) Dialectic of Sex. London: Paladin.

[11]. Frisch, A. L. and Caruso, J. M. (1996). “Criminalization Of Women”. In R. Roberts, (ed) HelpingBattered Women: New Perspectives and Remedies. (pp 102-131) New York: Oxford University Press.

[12]. Giddens, A. S. (2006) Sociology. Polity Press, Cambridge.

[13]. Haralambos, M and Heald, R. (1980).Sociology: Themes and perspectives.Oxford University Press.

[14]. Haralambos, M. and Holborn, M. (2000). Sociology: Themes and Perspective $\left(5^{\text {th }}\right.$ ed.); London: Harper-Collins Publishing Ltd.

[15]. Haralambos, M. and Holborn, M. (2004). Sociology: Themes and Perspective (6 ${ }^{\text {th }}$ ed.); London: Harper-Collins Publishing Ltd.

[16]. Okolo, G. U. (2004).Violence Against Women. CalabarBaye Communications.

[17]. Okolo, G. U. (2006). Marital Violence And Labour Productivity Of Women In Regular Employment: Unpublished PhD thesis.

[18]. Olakunle, F. (2011). Domestic Violence in Two Culturally Different Communities in Nigeria.Pan-African Social Science Review. No. December 2011. Pp. 119-219

[19]. Robert, A. R. (1996). “Myths and Realities Regarding Battered Women”. In A. R. Roberts (ed) Helping Battered Women: New Perspectives And Remedies. (pp 3-12) New York: Oxford University Press.

[20]. Straus, M. A. and Gelles, R. J. (1986)‘Societal Change and Change in Family Violence from 1975 to 1985 as Revealed by Two National Surveys' Journal of Marriage and the Family, 48.

[21]. Tiger, L. and Fox R. (1972).The Imperial Animal. London: Secker and Warburg.

[22]. World health organization (2000) Data Base on Violence Against Women (2000) In the World's Women, (2000): Trends and statistics (United Nations). http://unstats.un.org/unsd/demogrphic/ww2000/table6c.htm 